\title{
Prevalência internacional de cefaleia em transtorno depressivo: uma revisão sistemática
}

\author{
Anderson Sousa Martins da Silva1 ${ }^{(D)}$, Ciro Oliveira de Marco $^{2}$ (D) Wélissa da Silva Moura ${ }^{2}$ (D), \\ Yasmin Vieira Nolasco de Carvalho ${ }^{2}$ iD, Flavia Mariana Irber $^{2}$ (D) Victoria Camargos de Oliveira $^{2}$ (D), \\ João Mauricio Castaldelli-Maia' ${ }^{1}$
}

Universidade de São Paulo, São Paulo, Brasil

${ }^{2}$ Hospital Municipal Professor Dr. Alípio Correa Netto, São Paulo, Brasil.

\section{Introdução}

A cefaleia e o transtorno depressivo estão entre as doenças mais incapacitantes do mundo, segundo a Organização Mundial da Saúde. Estudos epidemiológicos e clínicos demonstraram uma associação entre estas duas etiologias, sendo uma associação bidirecional, o que significa que a presença de uma aumenta as chances de desenvolvimento do outra.

\section{Objetivo}

Avaliar a taxa de prevalência internacional de cefaleia no transtorno depressivo.

\section{Metodologia}

Foi realizada uma revisão sistemática da literatura utilizando a estratégia de busca: ("Headache"[Mesh]) AND "Depressive Disorder"[Mesh] nas bases de dados da PUBMED. Não houve restrições de idade, populações, settings, datas e países de origem. Foram selecionados artigos publicados até abril de 2021, em língua inglesa, portuguesa e espanhola.

\section{Resultados}

Nossa estratégia de busca encontrou 275 artigos, dos quais 16 preencheram nossos critérios de inclusão. Quanto ao continente de realização dos estudos, 37.5\% foram na América, 37.5\% na Ásia e 25\% na Europa. Houve uma maior prevalência do gênero feminino com uma proporção de feminino/masculino de 1.45, ressaltando que $25 \%$ dos artigos não descreverem os gêneros avaliados. Para o diagnostico de transtorno depressivo $50 \%$ dos artigos utilizaram o Manual de Diagnóstico e Estatística dos Transtornos Mentais Quarta Edição e para cefaleia 31.5\% utilizaram a International Classification of Headache Disorders Second Edition. A mediana de participantes foi de 605.5 , variando de 102 a 64.460 . A mediana da prevalência foi de $42.4 \%$ variando de 15.6 a $90.4 \%$.

\section{Conclusão}

A alta prevalência encontrada reforça a necessidade de prestar maior atenção a essa comorbidade e gerenciar as cefaleias de forma adequada, além do tratamento para o transtorno depressivo.

Palavras-chave: Cefaleia, Depressão, Prevalência, Comorbidade, Cefaleia do tipo tensional. 